\title{
Cellular Cholesterol Distribution Influences Proteolytic Release of the LRP-1 Ectodomain
}

\author{
Bassil Dekky ${ }^{1,2}$, Amandine Wahart1,2, Hervé Sartelet1,2, Michaël Féré2,3,4, \\ Jean-François Angiboust ${ }^{2,3,4}$, Stéphane Dedieu ${ }^{1,2}$, Olivier Piot ${ }^{2,3,4}$, Jérôme Devy ${ }^{1,2}$ and \\ Hervé Emonard1,2*
}

'Laboratoire de Signalisation et Récepteurs Matriciels, UFR de Sciences Exactes et Naturelles, Université de Reims Champagne-Ardenne, Reims, France, ${ }^{2}$ CNRS, Matrice Extracellulaire et Dynamique Cellulaire, UMR 7369, Reims, France, ${ }^{3}$ MéDIAN-Biophotonique et Technologies pour la Santé, UFR de Pharmacie, Université de Reims Champagne-Ardenne, Reims, France, ${ }^{4}$ Plateforme d'Imagerie Cellulaire et Tissulaire, Université de Reims Champagne-Ardenne, Reims, France

Low-density lipoprotein receptor-related protein-1 (LRP-1) is a multifunctional matricellular receptor composed of a large ligand-binding subunit (515-kDa $\alpha$-chain) associated with a short trans-membrane subunit (85-kDa $\beta$-chain). LRP-1, which exhibits both endocytosis and cell signaling properties, plays a key role in tumor invasion by regulating the activity of proteinases such as matrix metalloproteinases (MMPs). LRP-1 is shed at the cell surface by proteinases such as membrane-type 1 MMP (MT1-MMP) and a disintegrin and metalloproteinase-12 (ADAM-12). Here, we show by using biophysical, biochemical, and cellular imaging approaches that efficient extraction of cell cholesterol and increased LRP-1 shedding occur in MDA-MB-231 breast cancer cells but not in MDA-MB-435 cells. Our data show that cholesterol is differently distributed in both cell lines; predominantly intracellularly for MDA-MB-231 cells and at the plasma membrane for MDA-MB-435 cells. This study highlights the relationship between the rate and cellular distribution of cholesterol and its impact on LRP-1 shedding modulation. Altogether, our data strongly suggest that the increase of LRP-1 shedding upon cholesterol depletion induces a higher accessibility of the sheddase substrate, i.e., LRP-1, at the cell surface rather than an increase of expression of the enzyme.

Keywords: LRP-1, low-density lipoprotein receptor-related protein-1, ectodomain, cholesterol, shedding, Raman microspectroscopy

\section{INTRODUCTION}

The low-density lipoprotein receptor-related protein-1 (LRP-1) is a large heterodimeric receptor composed of an heavy extracellular chain, the $515-\mathrm{kDa} \alpha$-chain, non-covalently associated with a light transmembrane chain, the $85-\mathrm{kDa} \beta$-chain (Emonard et al., 2014). The extracellular $\alpha$-chain exhibits four cystein-rich complement-type repeats which bind more than 40 ligands, including proteinases and proteinase:inhibitor complexes (Etique et al., 2013). Motifs of the intracellular part of the $\beta$-chain activate endocytosis and signaling pathways (Lillis et al., 2005), which drive numerous biological functions and play a key role in the development of many pathological disorders (Lillis et al., 2008; Van Gool et al., 2015). LRP-1 invalidation in mice is lethal at early stage of embryogenesis (Herz et al., 1992). We previously demonstrated that LRP-1 promotes invasion of malignant cells by modulating focal complex composition (Dedieu et al., 2008). 
Low-density lipoprotein receptor-related protein-1 is broadly expressed in multiple cell types such as mesenchymal and epithelial cells (Emonard et al., 2014). Its expression is regulated by hormones and growth factors that induce different responses depending on cell types. Cell surface LRP-1 is cleaved by shedding to generate soluble LRP-1 ectodomain composed of the entire extracellular $\alpha$-chain linked to the extracellular part of the $\beta$-chain which was first discovered in plasma (Quinn et al., 1997). The first LRP-1 sheddase was characterized in human choriocarcinoma BeWo cells as a metalloproteinase (Quinn et al., 1999). More recently our group identified a disintegrin and metalloproteinase-12 (ADAM-12) and membrane-type 1 matrix metalloproteinase (MT1-MMP; Selvais et al., 2009, 2011). Several proteolytic enzymes belonging to other proteinases families have also been identified (for a review, Emonard et al., 2014).

Shedding is a closely regulated process that controls most of types I and II transmembrane proteins levels at cell surface (Hartmann et al., 2013). Cellular cholesterol depletion stimulates shedding of the interleukin-6 receptor (Matthews et al., 2003) and CD30 antigen (von Tresckow et al., 2004). By comparing two cell lines exhibiting different levels of cholesterol (conventional human fibrosarcoma HT1080 cells and an epithelioid variant with a twofold higher cell cholesterol content), we previously showed that low cell cholesterol level promotes LRP-1 shedding (Selvais et al., 2011).

Cholesterol is widely expressed at cell surface of mammalian cells but can also be located in the cytosolic compartment where it could play a role in transmembrane protein trafficking (Mukherjee et al., 1998). In the present study, we evaluated the efficiency of LRP-1 shedding process in cell lines expressing either cholesterol at plasma membrane or in cytosolic compartment (Nieva et al., 2012). We demonstrated by using different imaging approaches, that efficient extraction of cholesterol and increased LRP-1 shedding occur predominantly in cells exhibiting cholesterol at cell surface.

\section{MATERIALS AND METHODS}

\section{Reagents and Antibodies}

Dulbecco's modified Eagle medium (DMEM) and other cell culture reagents were purchased from Thermo Fisher Scientific (Illkirch, France). Fetal calf serum (FCS) was from Dutscher (Brumath, France). Filipin, methyl- $\beta$-cyclodextrin $(\mathrm{M} \beta \mathrm{CD})$ and other chemicals were from Sigma-Aldrich (Saint-Quentin Fallavier, France). Phosphate-buffered saline (PBS)-B (131 mM NaCl, $5.1 \mathrm{mM} \mathrm{Na} \mathrm{HPO}_{4}$, and $1.5 \mathrm{mM}$ $\mathrm{KH}_{2} \mathrm{PO}_{4}$ ) was from bioMérieux (Craponne, France). Anti-LRP-1 $\alpha$-chain (mouse, clone 8G1) was from Calbiochem (Merck Biosciences, distributed by VWR International, Strasbourg, France). Goat polyclonal antibodies directed against $\beta$-actin were from Abcam (Paris, France). Horseradish peroxidase (HRP)-conjugated anti-mouse antibodies were from Cell Signaling Technology (distributed by Ozyme, MontignyLe-Bretonneux, France) and HRP-anti-goat antibodies from Sigma-Aldrich.

\section{Cell Culture}

Human breast cancer cell lines MDA-MB-231 and MDA-MB435 were obtained from the American Type Culture Collection. MDA-MB-231 and MDA-MB-435 cells were cultured in DMEM containing 1 and $4.5 \mathrm{~g} / \mathrm{l}$ glucose, respectively. Culture media were supplemented with $10 \%$ FCS, 100 units/ml penicillin and $10 \mathrm{mg} / \mathrm{ml}$ streptomycin. For cell imaging, FCS was depleted in lipoproteins following a procedure adapted from the Havel et al. (1955). Cells were grown at $37^{\circ} \mathrm{C}$ in a humid atmosphere $(5 \%$ $\mathrm{CO}_{2}$ and $95 \%$ air). As cellular cholesterol content depends, at least in part, on cellular confluency state (Takahashi et al., 2007), all experiments were carried out at similar cell densities.

\section{M $\beta C D$ Treatment and Cholesterol Assay}

The water-soluble M $\beta C D$ forms soluble inclusion complexes with cholesterol, enhancing thus its solubility in aqueous solution (Pitha et al., 1988) and is classically used to extract cholesterol from cultured cells. In the present study, cells were treated with $\mathrm{M} \beta C D(0-20 \mathrm{mM})$ in FCS-free medium for $30 \mathrm{~min}$ at $37^{\circ} \mathrm{C}$. Cells were then harvested in reaction buffer $(0.1 \mathrm{M}$ potassium phosphate, $\mathrm{pH} 7.4,50 \mathrm{mM} \mathrm{NaCl}, 5 \mathrm{mM}$ cholic acid, and $0.1 \%$ Triton X-100) and sonicated. Cholesterol content was quantified using the Amplex Red cholesterol assay kit (Invitrogen distributed by Thermo Fisher Scientific), as recommended by the manufacturer. Reactions proceeded for $20 \mathrm{~min}$ at $37^{\circ} \mathrm{C}$. Alternatively, after treatment with $\mathrm{M} \beta \mathrm{CD}$ cells were washed with PBS and further incubated in FCS-free medium for $24 \mathrm{~h}$. Twenty four-hour conditioned media were concentrated and shedding of LRP-1 was analyzed by western blotting.

\section{Raman Microspectroscopy Analysis}

Cells $\left(3 \times 10^{4}\right)$ were seeded in 6-well plates containing $\mathrm{CaF}_{2}$ substrates (Crystan, Ltd., Dorset, UK), and $48 \mathrm{~h}$ later cells were fixed with $4 \%$ cold paraformaldehyde (PFA) for $30 \mathrm{~min}$ at room temperature. After fixing, cells were washed three times with PBS and water, before drying to be analyzed with Raman spectroscopy.

Raman spectra were acquired from each sample using a LabRAM Raman spectrometer (Jobin Yvon, Horiba, Lille France). The setup contained a laser diode at $660 \mathrm{~nm}$ supplying an excitation beam of $25 \mathrm{~mW}$ at the sample. The laser beam was focused onto the sample using a Leica HCX PL FluoTar $\mathrm{x} 100$ objective $(\mathrm{NA}=0.75)$. The same objective collected the light scattered from the sample. An edge filter permitted to reject the laser reflection and the Rayleigh scattering. A grating of $1200 \mathrm{~g} / \mathrm{mm}$ ensured the dispersion of the Raman Stokes signal with a spectral resolution of $4 \mathrm{~cm}^{-1}$. The intensity of the Raman vibrations was measured using a deep depletion charge-coupled device (CCD) detector. The spectra were collected on a total spectral range from 400 to $4000 \mathrm{~cm}^{-1}$, with an acquisition time of $40 \mathrm{~s}$ per spectrum. For each cell, a number of five spectra were collected at the level of the cytoplasm. Raman data were then baseline-corrected using linear segments, slightly smoothed (three points averaging) and normalized on the basis of the total integrated intensity. The five spectra recorded on each cell were averaged. Up to this point, the acquisition and processing 
of the data were performed using Labspec 5 software (Horiba Jobin Yvon, Lille France). Then, Raman data were submitted to statistical multivariate processing corresponding to principal component analysis (PCA). PCA operated via a home-made interface using Matlab Toolbox (MathWorks ${ }^{\circledR}$ ). Mean-centered data were used for PCA.

\section{Cholesterol Staining and Cell Imaging}

Cells $\left(5 \times 10^{4}\right)$ were seeded onto gelatin-coated glass slides and cultured in media containing lipoproteins-depleted FCS for $24 \mathrm{~h}$ at $37^{\circ} \mathrm{C}$. Then, cells were treated or not with $\mathrm{M} \beta \mathrm{CD}$ and fixed in 3\% paraformaldehyde for $60 \mathrm{~min}$ at room temperature. After three washes in PBS, cells were incubated in glycine $(1.5 \mathrm{mg} / \mathrm{ml}$ in PBS-B) for $10 \mathrm{~min}$ and then stained with filipin $(0.05 \mathrm{mg} / \mathrm{ml}$ in PBS-B) for $2 \mathrm{~h}$ at room temperature. Filipin-stained cell preparations were analyzed using a Zeiss LSM 710 confocal laser scanning microscope with the $63 x$ oil-immersion objective and Zen operating system (Zeiss, Heidelberg, Germany). All acquisitions were performed with UPlan $\mathrm{x}$ 63, 1.4 numerical aperture objective by exciting filipin with a chameleon infrared laser tuned at $740 \mathrm{~nm}$. Emitted fluorescence was detected through the appropriate filter and twenty images were captured with a $0.25-\mu \mathrm{m}$ z-step. DIC images were acquired simultaneously with the reflected light images using a TPMT module. Images were treated with Amira ${ }^{\mathrm{TM}}$ software (v6.0.1, FEI visualization Sciences Group, Merignac, France) and projection through each z-stack was merged with DIC images.

\section{RNA Isolation, RT-PCR, and Real-Time-PCR}

Total RNAs were isolated and purified with Extract-All kit (Eurobio Laboratories, Courtaboeuf, France). Reverse transcription (RT) and real-time PCR were performed with Verso SYBR 2-Step QRT Rox kit (AB-4113/A) and Absolute QPCR SYBR Green Rox (AB-1162/B), respectively (Thermo Fisher Scientific). Quantitative PCR was carried out on a Chromo4 Real-Time Detector (Bio-Rad Laboratories, Marne-laVallée, France). Data were normalized to ribosomal proteins L32 (RPL32) and S18 (RS18) or to $\beta$-actin. Primers for LRP-1 (Dedieu et al., 2008) and $\beta$-actin (Langlois et al., 2010) were previously described. Primers were synthesized as follows: for MT1-MMP, AACCAAGTGATGGATGGATACC and CTCCTTAATGTGCT TGGGGTAG; for transmembrane form of ADAM-12, ADAM12L, GGGCTGTAGCTGTCAAATGG and CTGACTTCCGGCA GGTTAAA; for RPL32, CATTGGTTATGGAAGCAACAAA and TTCTTGGAGGAAACATTGTGAG; for RS18, GCAGAAT CCACGCCAGTACAA and GCCAGTGGTCTTGGTGTGCT (Eurogentec France, Angers, France). Results shown are representative of three independent experiments.

\section{Sample Preparation and Western Blot Analysis}

Cells treated or not with $\mathrm{M} \beta \mathrm{CD}$ were then washed with PBS and further incubated with FCS-free medium for $24 \mathrm{~h}$. Twenty fourhour-conditioned media were cleared by centrifugation $(1,000 \mathrm{~g}$ at $4^{\circ} \mathrm{C}$ for $10 \mathrm{~min}$ ) and concentrated 50 -fold with Vivaspin centrifugal concentrators (Sartorius Stedim Biotech, distributed by Dutscher) following manufacturer's recommendations. Cells were scraped in ice-cold lysis buffer (10 mM CHAPS, $20 \mathrm{mM}$ HEPES (pH 7.4), $150 \mathrm{mM} \mathrm{NaCl}, 2 \mathrm{mM} \mathrm{CaCl}_{2}, 1 \mathrm{mM}$ phenylmethylsulfonylfluroide supplemented with proteinase inhibitor cocktail from Sigma-Aldrich). After sonication, the remaining pellet was discarded by centrifugation $\left(10,000 \mathrm{~g}\right.$ at $4^{\circ} \mathrm{C}$ for $10 \mathrm{~min}$ ).

Western blotting was performed as previously described (Selvais et al., 2011) using 5\% polyacrylamide gel for LRP$1515 \mathrm{kDa} \alpha$-chain and $10 \%$ polyacrylamide gel for $\beta$-actin. Primary antibodies were used at 1/4000 for LRP-1 $\alpha$-chain and $1 / 1000$ for $\beta$-actin. Samples were normalized with respect to cell protein amount, which was determined using BC assay protein quantitation kit (Thermo Scientific, distributed by Interchim, Montluçon, France). Each lane was loaded with cell lysates equivalent of $40 \mu \mathrm{g}$ protein, or corresponding amounts of conditioned medium. Immunoreactive bands were revealed using the ECL chemiluminescence kit (Amersham Biosciences, distributed by Dutscher), acquired using the Odyssey ${ }^{\circledR}$ Fc DualMode LI-CORE Imaging System (Biosciences Biotechnology, distributed by Eurobio Laboratories) and quantified using ImageJ software. $\beta$-actin antibodies were used for normalization. Immunoblots presented are representative of at least three independent experiments.

\section{Statistical Analysis}

Data were analyzed using unpaired two-tailed Student's $t$-test. Differences were considered significant for $P<0.05$. Values are reported as mean $\pm \mathrm{SD}$.

\section{RESULTS}

We previously reported in the human fibrosarcoma HT1080 cell line the correlation between cell cholesterol amount and efficiency of LRP-1 shedding (Selvais et al., 2011). In the present study we investigated the possible role of cholesterol distribution by using two different breast cancer cell lines MDA-MB-231 and MDA-MB-435 cells, one expressing cholesterol in the cytosol and the other at the plasma membrane (Nieva et al., 2012).

\section{MDA-MB-231 and MDA-MB-435 Breast Cancer Cells Exhibit Different Lipid Phenotypes}

We first explored the lipid phenotype of MDA-MB-231 and MDA-MB-435 cells by Raman microspectroscopy. Spectra collected on the cytoplasmic compartment of the two cell lines were processed by PCA, an exploratory unsupervised method of multivariate data processing. PCA is commonly used to explore the intra- and inter-group variabilities based on the Raman signals of the cells (Poplineau et al., 2011). A distinction between the two cell types is clearly visible on the score plot constructed on the two first components (Figure 1A). The distinction relies mainly on the first principal component (PC1) that exhibits signals assigned to lipid vibrations (Figure 1B). Indeed, the spectral zones grayed on the display of the first component, 


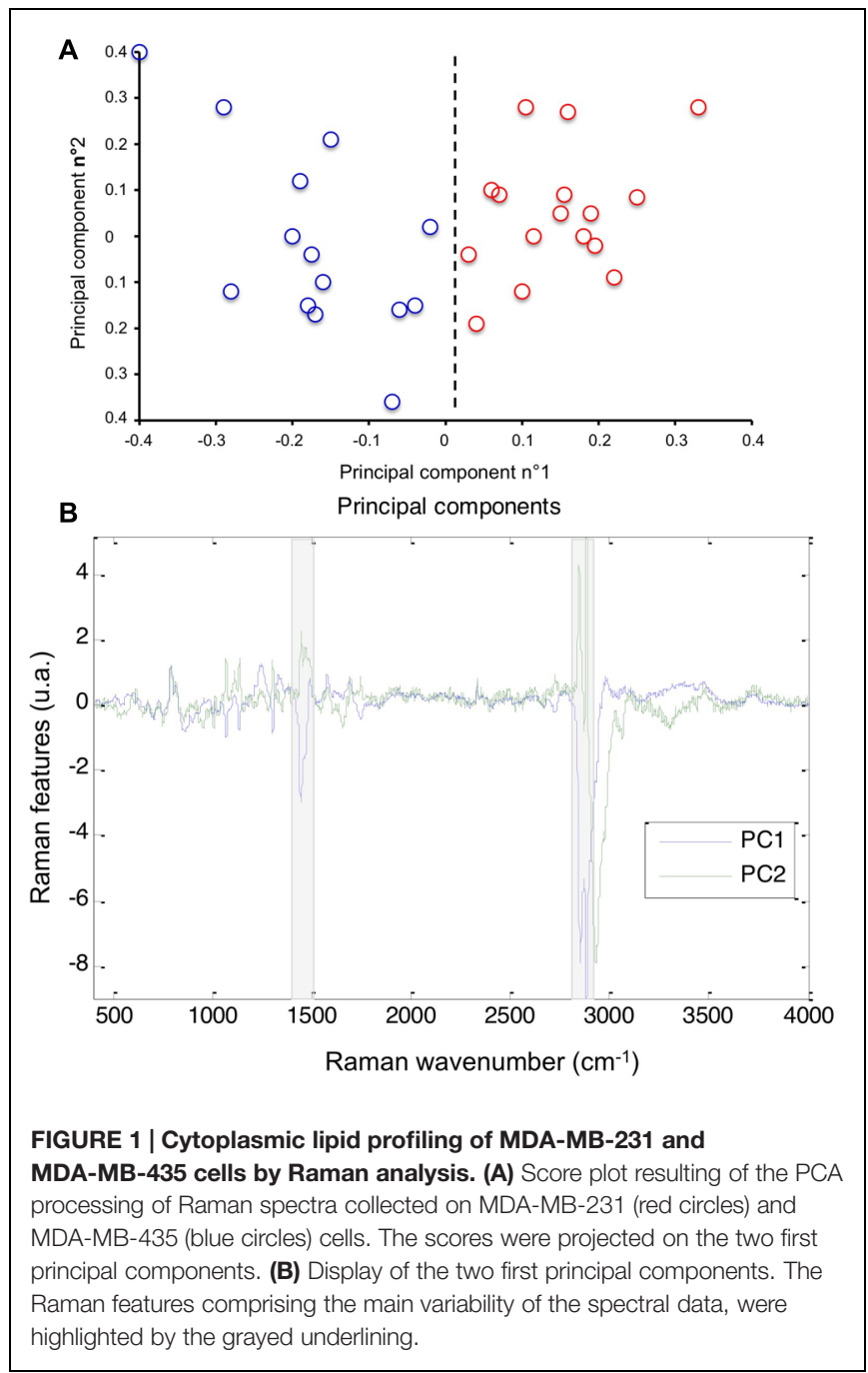

centered at 1450 and $2850 \mathrm{~cm}^{-1}$, are assigned to bending and stretching vibrations of lipid $\mathrm{CH}_{2}$ and $\mathrm{CH}_{3}$ groups respectively. This analysis reflects that the lipid contribution of the cytoplasm as probed by Raman spectroscopy allows distinguishing MDAMB-231 and MDA-MB-435 cells. The same Raman features are also recovered on the second principal component (PC2), reflecting their involvement in the intra-group variability of these cellular samples.

\section{Efficiency of Cholesterol Depletion Depends on its Cellular Distribution}

We next investigated using biochemical and cellular imaging analyses whether the biophysical analysis findings showing different cytoplasmic lipids-based discrimination between MDAMB-231 and MDA-MB-435 cells was confirmed for cholesterol.

Similar cholesterol content was quantified in untreated MDAMB-231 and -435 cells, with $11.1 \pm 2.9 \mu \mathrm{g}$ cholesterol/mg cell protein and $10.3 \pm 2.9 \mu \mathrm{g}$ cholesterol/mg cell protein, respectively. MDA-MB-231 and -435 cells were then treated with increasing concentrations of $\operatorname{M\beta CD}(5,10$, and $20 \mathrm{mM})$

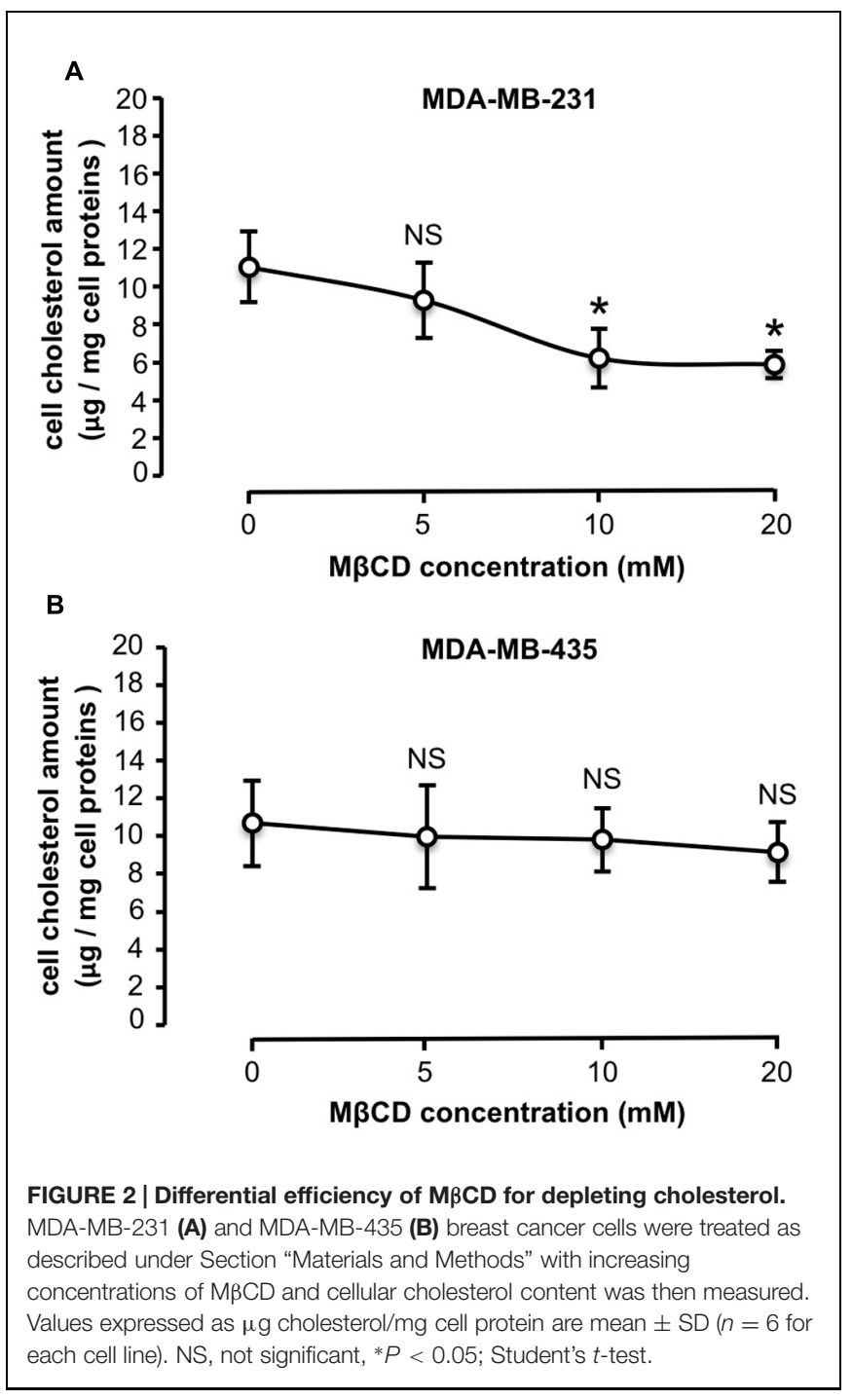

to extract cholesterol and the effect on cell cholesterol depletion was measured (Figure 2). Five millimolar $M \beta C D$ had no effect on cell cholesterol amount in the two cell lines. In MDA-MB231 cells a depletion peak of cell cholesterol was observed at $10 \mathrm{mM}$ of $\mathrm{M} \beta \mathrm{CD}$ (Figure 2A). In contrast, in MDA-MB-435 cells cell cholesterol amount did not vary upon $\mathrm{M} \beta \mathrm{CD}$ treatment (Figure 2B). Filipin-labeled cells revealed that cholesterol was predominantly distributed in cytosol for MDA-MB-231 cells (Figure 3A, white arrow) and in plasma membrane in MDA-MB435 cells (Figure 3C, red arrow). Interestingly, efficient extraction of cholesterol upon $\mathrm{M} \beta \mathrm{CD}$ treatment was observed in MDA-MB231 cells (Figure 3B) but not in MDA-MB-435 cells (Figure 3D).

\section{Decrease of Cell Cholesterol Content Potentiates Shedding of LRP-1 without Affecting the Expression of LRP-1, MT1-MMP, and ADAM-12}

We then investigated if modulation of cell cholesterol amount by $\mathrm{M} \beta \mathrm{CD}$ treatment had an impact on LRP-1 shedding process in 


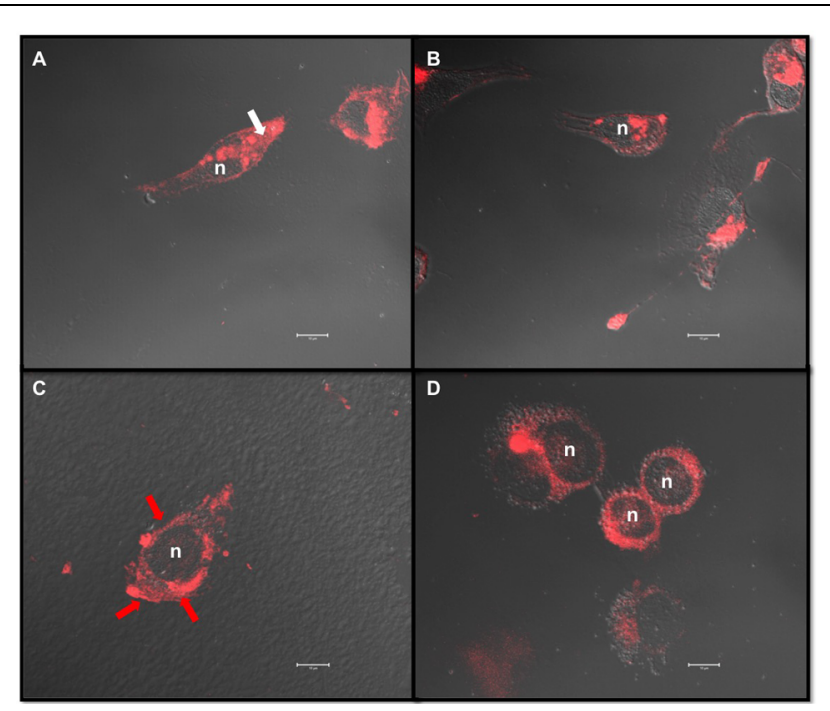

FIGURE 3 | M $\beta C D$ exhibits different effects on cholesterol depletion in MDA-MB-231 and MDA-MB-435 breast cancer cell lines. MDA-MB-231 $(\mathbf{A}, \mathbf{B})$ and MDA-MB-435 (C,D) cells were treated as described under Section "Materials and Methods" with vehicle alone (A,C) or $10 \mathrm{mM} \mathrm{M \beta CD}$ (B,D). Cells were fixed in $3 \%$ PFA and treated with filipin $(50 \mu \mathrm{g} / \mathrm{mL})$ for $2 \mathrm{~h}$ at room temperature. Projection of each z-stack acquired through confocal microscopy images was merged with DIC images. Filipin labels free cholesterol present in the membranes (red arrow) and in the cytosol (white arrow). Scale bar: $10 \mu \mathrm{m}, \mathrm{n}$, nucleus.

MDA-MB-231 and -435 cells (Figure 4), as previously reported for the human fibrosarcoma HT1080 cells (Selvais et al., 2011). In the absence of M $\beta C D$ treatment, LRP-1 expression is similar in MDA-MB-231 and -435 cells (Figures 4A,B). LRP-1 levels are also comparable in CHAPS extracts from MDA-MB-231 and -435 cells as well as in their respective conditioned media (Figure 4C). By using $\mathrm{M} \beta \mathrm{CD}$ at $10 \mathrm{mM}$, a concentration that efficiently depleted MDA-MB-231 cells in cholesterol (Figure 2A), we observed a large decrease of LRP-1 in the CHAPS extracts of MDA-MB-231 cells that was accompanied by a twofold increase of soluble LRP-1 in conditioned media (Figures 4C,D). In contrast $\mathrm{M} \beta \mathrm{CD}$ treatment, which did not modify cholesterol amount in MDA-MB-435 cells (Figure 2B), had no effect on LRP-1 shedding in these cells (Figures 4C,D).

To exclude that differences of LRP-1 shedding levels that we observed between the two breast cancer cell lines could be attributed to modulations of LRP-1, MT1-MMP and/or ADAM12, its main sheddases (Selvais et al., 2011), we tested the effect of $M \beta C D$ treatment on the expression of these three molecules. Neither LRP-1 mRNA (Figure 5A) nor MT1-MMP mRNA (Figure 5B) and ADAM-12 (Figure 5C) levels were affected by $10 \mathrm{mM} \mathrm{M} \beta \mathrm{CD}$ treatment.

\section{DISCUSSION}

In the present study we investigated the relationship between cholesterol cell distribution and LRP-1 shedding efficiency. For this purpose, we used MDA-MB-231 and MDA-MB-435 cells,
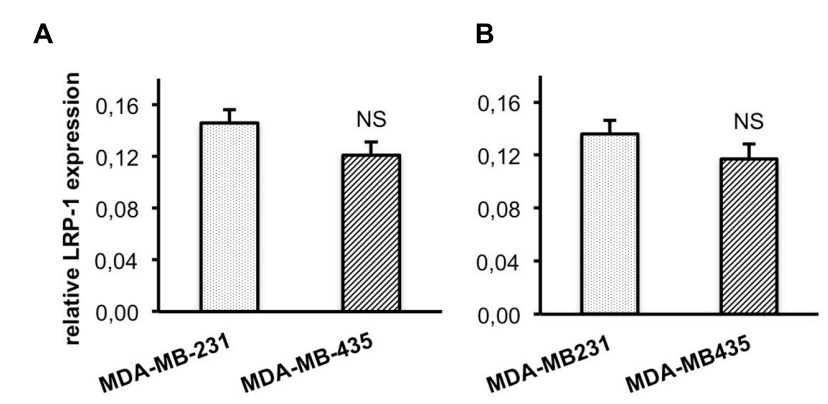

C
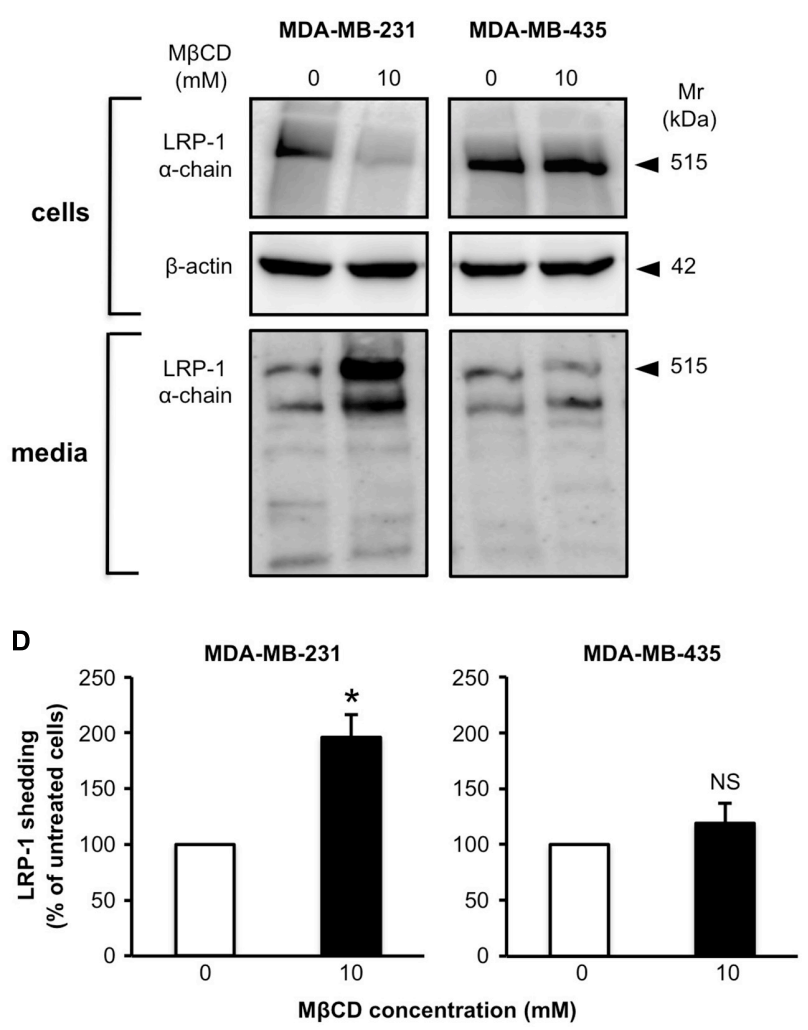

FIGURE 4 | Depletion of cellular cholesterol by M $\beta C D$ increases shedding of the LRP-1 ectodomain. MDA-MB-231 and MDA-MB-435 cells were treated as described under Section "Materials and Methods" with vehicle alone or $10 \mathrm{mM} M \beta C D$. Basal level expression of LRP-1 was measured by quantitative real-time PCR. Data were normalized to ribosomal proteins RPL32 (A) and RS18 (B). Western blotting of LRP-1 $\alpha$-chain and $\beta$-actin was performed from cell lysates, and blotting of LRP- $1 \alpha$-chain in corresponding amounts of 24-h conditioned medium. Data are from a representative experiment (C). LRP-1 ectodomain shedding was quantified on Western blots of LRP- $1 \alpha$-chain released in the concentrated conditioned medium (D). NS, not significant, ${ }^{P} P<0.05$; Student's $t$-test.

two cancer cell lines recently described for exhibiting different patterns of cholesterol localization, respectively in the cytoplasm and in the plasma membrane (Nieva et al., 2012). Treatment by $\mathrm{M} \beta \mathrm{CD}$ decreased amount of cholesterol that was mainly localized in cytoplasm and stimulated removal of cell-surface LRP-1. In contrast, such a treatment had no effect on cholesterol levels predominantly distributed at the plasma membrane and on the 

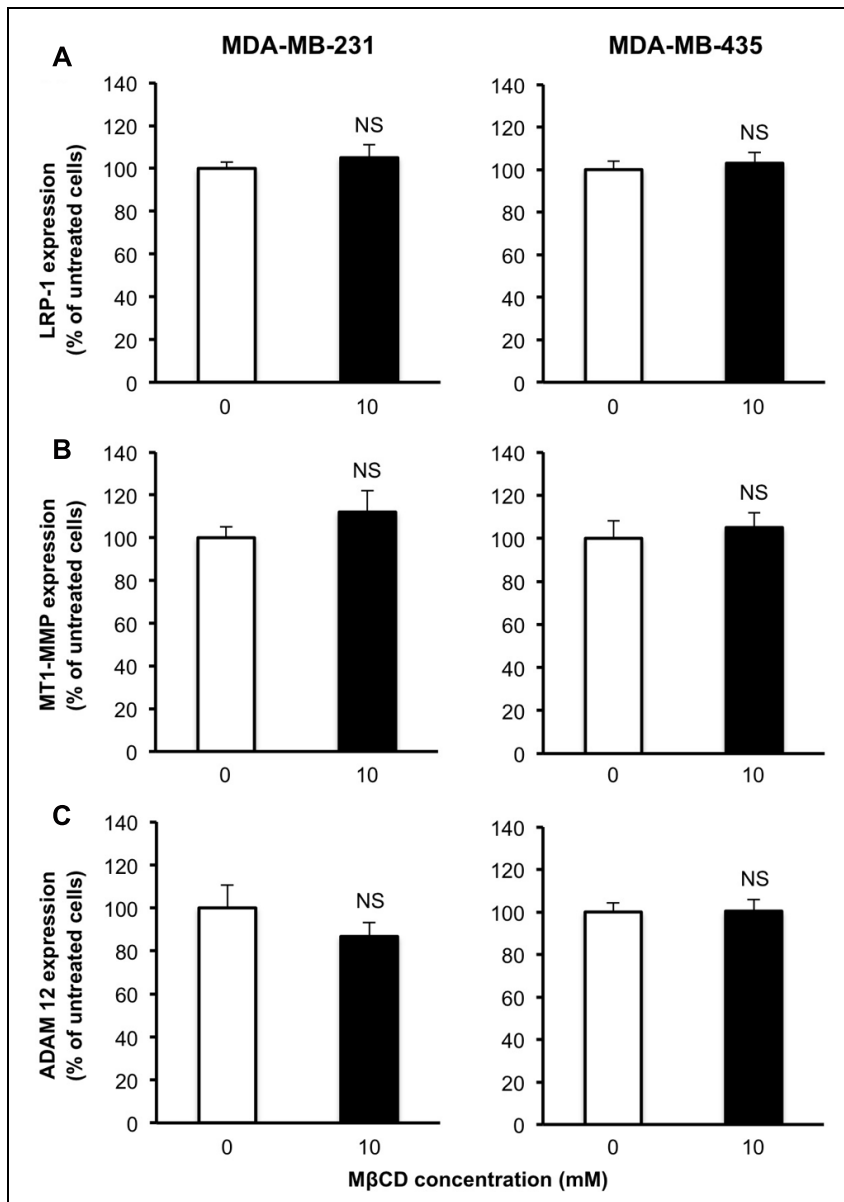

FIGURE 5 | Depletion of cellular cholesterol by $M \beta C D$ has no effect on the expression of LRP-1 or its sheddases MT1-MMP and ADAM-12. Quantitative real-time PCR of LRP-1 (A), MT1-MMP (B) and ADAM-12 (C) mRNA levels. After normalization to $\beta$-actin mRNA amounts (Langlois et al. 2010), data were presented as a percentage of untreated cells. Values are mean \pm SD ( $n=3$ for each cell line). NS, not significant; Student's $t$-test.

release of the LRP-1 ectodomain. These discrepancies are not related to modified expression of LRP-1 and/or of its sheddases, MT1-MMP and ADAM-12. Altogether, these data suggested that cell distribution of cholesterol affects the shedding of LRP-1 from the cell surface.

The lipid profiling of MDA-MB-231 and MDA-MB435 breast cancer cells was first investigated using Raman microspectroscopy. Raman microspectroscopy was performed on single living cells. The non-destructive and label free spectral analysis permitted to highlight the lipid contribution of the cytoplasmic compartment as a distinctive biochemical characteristic between the two cell types. The discriminant potential of this biophotonic approach was shown by a standard PCA. This unsupervised processing revealed also a marked intra-group variability as visible on the score plot of Figure 1. The origin of this variability could be investigated by carrying out spectral imaging at the cellular level (Abramczyk et al., 2015). Innovative devices, based on stimulate Raman scattering, have been recently proven to map the cellular lipid distribution in video-rate imaging (Ramachandran et al., 2015). Raman microspectroscopy allowed us to partially discriminate the two cell lines on the basis of their cytoplasmic spectral signature of lipids, including cholesterol as previously described (Nieva et al., 2012). Recent data obtained by fluorescence microscopy study after filipin staining indicated that cholesterol was mainly concentrated in cytoplasm of MDA-MB-231 cells while it was mostly distributed in plasma membrane of MDA-MB-435 cells (Nieva et al., 2012). In the present study, the observation of filipin-stained MDA-MB-231 and MDA-MB-435 cells by confocal microscope confirmed such findings.

The efficient depletion of cytoplasmic cholesterol in MDAMB-231 cells after treatment with M such a compound can pass through plasma membrane for extracting cholesterol from membranes of cytosolic vesicles, as previously reported for removal of lysosomal cholesterol in skin fibroblasts (Swaroop et al., 2012). Unability of M $\beta C D$ to extract cholesterol mainly distributed in plasma membrane of MDA-MB-435 cells (Figures 2 and 3) is rather surprising. $\mathrm{M} \beta \mathrm{CD}$ treatment has indeed been often associated with lipid raft disintegration (Zimina et al., 2005). The lipid rafts result of the interaction between cholesterol with sphingolipids in the outer exoplasmic leaflet of the lipid bilayer of cellular membranes. Cholesterol also interacts with phospholipids in the inner cytoplasmic leaflet of the lipid bilayer. Lipid rafts are considered to be present as a liquid-ordered phase while phospholipid-rich domains are in a disordered state (Simons and Ehehalt, 2002). Giant plasma-membrane vesicles represent a valuable physiological tool to investigate lipid phase separation (Baumgart et al., 2007). Using this model, Levental et al. (2009) demonstrated a cholesterol dependence of phase separation in complex membranes at physiological conditions. Moreover, using the same experimental model Sanchez et al. (2011) demonstrated that $\mathrm{M} \beta \mathrm{CD}$ preferentially removed cholesterol from a liquid disordered phase. A computational microscopy study recently confirmed that cholesterol was preferentially extracted from the disordered regions compared to liquidordered domains of lipid model membranes (López et al., 2013). Altogether, these data suggest that $\mathrm{M} \beta \mathrm{CD}$-resistant cholesterol in membranes of the MDA-MB-435 cells reflects their richness in lipid rafts. This will be evaluated in a future experiment by atomic force microscopy, as recently proposed (Cremona et al., 2015).

The increase of transmembrane receptor shedding was often related to decrease of cell cholesterol amount, possibly by disintegration of lipid rafts and dynamic interactions of the sheddase and its target (Matthews et al., 2003; von Tresckow et al., 2004; Zimina et al., 2005). We showed similar correlation of increase of LRP-1 shedding by MT1-MMP and cell cholesterol decrease upon M $\beta C D$ treatment in HT1080 cells (Selvais et al., 2011). Interestingly, our present study highlights a relationship between cholesterol cell distribution and LRP1 shedding efficiency. Fluorescence imaging in living $\mathrm{CHO}$ cells clearly evidenced that intracellular cholesterol is mainly distributed in the endocytic recycling compartment and the trans-Golgi network (Mukherjee et al., 1998). However, the 
multiplicity of cholesterol transport systems makes difficult the establishment of specific trafficking route (Chang et al., 2006). Previous studies demonstrate that cholesterol intracellular trafficking and distribution, rather than total cholesterol levels, are regulatory factors in the $\beta$-amyloid precursor protein processing (Marzolo and $\mathrm{Bu}, 2009$ ). Malnar et al. (2012) proposed that cholesterol regulates the $\beta$-amyloid precursor protein processing by modulating APP expression at the cell surface. To our knowledge, no relationship between intracellular cholesterol distribution and LRP-1 localization has been proposed so far.

\section{CONCLUSION}

Our data suggest that intracellular cholesterol depletion may increase intracellular trafficking to cell surface of newly synthesized LRP-1 and/or recycled LRP-1 after endocytosis process. Consequently, enhancement of LRP-1 shedding upon cholesterol depletion should reflect a higher disponibility of the sheddase substrate, i.e., LRP-1, at the cell surface. However, the question whether intracellular cholesterol depletion has an impact on LRP-1 localization remains to be elucidated.

\section{REFERENCES}

Abramczyk, H., Surmacki, J., Kopeć, M., Olejnik, A. K., LubeckaPietruszewska, K., and Fabianowska-Majewska, K. (2015). The role of lipid droplets and adipocytes in cancer. Raman imaging of cell cultures: MCF10A, MCF7, and MDA-MB-231 compared to adipocytes in cancerous human breast tissue. Analyst 140, 2224-2235. doi: 10.1039/c4an $01875 c$

Baumgart, T., Hammond, A. T., Sengupta, P., Hess, S. T., Holowka, D. A., Baird, B. A., et al. (2007). Large-scale fluid/fluid phase separation of proteins and lipids in giant plasma membrane vesicles. Proc. Natl. Acad. Sci. U.S.A. 104, 3165-3170. doi: 10.1073/pnas.0611357104

Chang, T. Y., Chang, C. C. Y., Ohgami, N., and Yamauchi, Y. (2006). Cholesterol sensing, trafficking, and esterification. Annu. Rev. Cell Dev. Biol. 22, 129-157. doi: 10.1146/annurev.cellbio.22.010305.104656

Cremona, A., Orsini, F., Corsetto, P. A., Hoogenboom, B. W., and Rizzo, A. M. (2015). Reversible-dissolution of microdomains in detergent-resistant membranes at physiological temperature. PLoS ONE 10:e0132696. doi: 10.1371/journal.pone.0132696

Dedieu, S., Langlois, B., Devy, J., Sid, B., Schneider, C., Henriet, P., et al. (2008). LRP-1 silencing prevents malignant cell invasion despite increased pericellular proteolytic activities. Mol. Cell. Biol. 28, 2980-2995. doi: 10.1128/MCB. 02238-07

Emonard, H., Théret, L., Bennasroune, A. H., and Dedieu, S. (2014). Regulation of LRP-1 expression: make the point. Pathol. Biol. 62, 84-90. doi: 10.1016/j.patbio.2014.02.002

Etique, N., Verzeaux, L., Dedieu, S., and Emonard, H. (2013). LRP-1: a checkpoint for the extracellular matrix proteolysis. BioMed. Res. Int. 2013:152163. doi: $10.1155 / 2013 / 152163$

Hartmann, M., Herrlich, A., and Herrlich, P. (2013). Who decides when to cleave an ectodomain? Trends Biochem. Sci. 38, 111-120. doi: 10.1016/j.tibs.2012.12.002

Havel, R. J., Eder, H. A., and Bragdon, J. H. (1955). The distribution and chemical composition of ultracentrifugally separated lipoproteins in human serum. J. Clin. Invest. 34, 1345-1353. doi: 10.1172/JCI103182

Herz, J., Clouthier, D. E., and Hammer, R. E. (1992). LDL receptor-related protein internalizes and degrades uPA-PAI-1 complexes ansd is essential

\section{AUTHOR CONTRIBUTIONS}

$\mathrm{BD}, \mathrm{AW}, \mathrm{HS}, \mathrm{MF}, \mathrm{J}-\mathrm{FA}$ contributed to the acquisition and analysis of data for the work; SD, OP, and JD contributed to the conception, design of the work and to the analysis and interpretation of data for the work; HE contributed to the conception, design of the work and to the analysis and interpretation of data for the work and written the manuscript.

\section{FUNDING}

The work was supported by funding from the Centre National de la Recherche Scientifique (CNRS), the Université de Reims Champagne-Ardenne (URCA), the Région Champagne-Ardenne and the Ligue Nationale contre le Cancer (CCIR-GE, Conférence de Coordination Inter-Régionale du Grand Est).

\section{ACKNOWLEDGMENTS}

The authors thank Fanja Rabenoelina for excellent technical support as well as Dr. Laetitia Dimanche (EMD Serono, Billerica, MA, USA) for editorial assistance.

for embryo implantation. Cell 71, 411-421. doi: 10.1016/0092-8674(92) 90511-A

Langlois, B., Perrot, G., Schneider, C., Henriet, P., Emonard, H., Martiny, L., et al. (2010). LRP-1 promotes cancer cell invasion by supporting ERK and inhibiting JNK signaling pathways. PLoS ONE 5:e11584. doi: 10.1371/journal.pone.0011584

Levental, I., Byfield, F. J., Chowdhury, P., Gai, F., Baumgart, T., and Janmey, P. A. (2009). Cholesterol-dependent phase separation in cell-derived giant plasma membrane vesicles. Biochem. J. 424, 163-167. doi: 10.1042/BJ200 91283

Lillis, A. P., Mikhailenko, I., and Strickland, D. K. (2005). Beyond endocytosis: LRP function in cell migration, proliferation and vascular permeability. J. Thromb. Haemost. 3, 1884-1893. doi: 10.1111/j.1538-7836.2005. 01371.x

Lillis, A. P., Van Duyn, L. B., Murphy-Ullrich, J. E., and Strickland, D. K. (2008). LDL receptor-related protein 1: unique tissue-specific functions revealed by selective gene knockout studies. Physiol. Rev. 88, 887-918. doi: 10.1152/physrev.00033

López, C. A., de Vries, A. H., and Marrink, S. J. (2013). Computational microscopy of cyclodextrin mediated cholesterol extraction from lipid model membranes. Sci. Rep. 3:2071. doi: 10.1038/srep02071

Malnar, M., Kosicek, M., Lisica, A., Posavec, M., Krolo, A., Njavro, J., et al. (2012). Cholesterol-depletion corrects APP and BACE1 misstrafficking in NPC1-deficient cells. Biochim. Biophys. Acta 1822, 1270-1283. doi: 10.1016/j.bbadis.2012.04.002

Marzolo, M. P., and Bu, G. (2009). Lipoprotein receptors and cholesterol in APP trafficking and proteolytic processing, implications for Alzheimer's disease. Semin. Cell Dev. Biol. 20, 191-200. doi: 10.1016/j.semcdb.2008. 10.005

Matthews, V., Schuster, B., Schütze, S., Bussmeyer, I., Ludwig, A., Hundhausen, C., et al. (2003). Cellular cholesterol depletion triggers shedding of the human interleukin-6 receptor by ADAM10 and ADAM17 (TACE). J. Biol. Chem. 278, 38829-38839. doi: 10.1074/jbc.M210584200

Mukherjee, S., Zha, X., Tabas, I., and Maxfield, F. R. (1998). Cholesterol distribution in living cells: fluorescence imaging using dehydroergosterol as a fluorescent cholesterol analog. Biophys. J. 75, 1915-1925. doi: 10.1016/S00063495(98)77632-5 
Nieva, C., Marro, M., Santana-Codina, N., Rao, S., Petrov, D., and Sierra, A. (2012). The lipid phenotype of breast cancer cells characterized by Raman microspectroscopy: towards a stratification of malignancy. PLoS ONE 7:e46456. doi: 10.1371/journal.pone.0046456

Pitha, J., Irie, T., Sklar, P. B., and Nye, J. S. (1988). Drug solubilizers to aid pharmacologists: amorphous cyclodextrin derivatives. Life Sci. 43, 493-502. doi: 10.1016/0024-3205(88)90150-6

Poplineau, M., Trussardi-Régnier, A., Happillon, T., Dufer, J., Manfait, M., Bernard, P., et al. (2011). Raman microspectroscopy detects epigenetic modifications in living Jurkat leukemic cells. Epigenomics 3, 785-794. doi: 10.2217/epi.11.102

Quinn, K. A., Grimsley, P. G., Dai, Y. P., Tapner, M., Chesterman, C. N., and Owensby, D. A. (1997). Soluble low density lipoprotein receptor-related protein (LRP) circulates in human plasma. J. Biol. Chem. 272, 23946-23951. doi: $10.1074 /$ jbc. 272.38 .23946

Quinn, K. A., Pye, V. J., Dai, Y. P., Chesterman, C. N., and Owensby, D. A. (1999). Characterization of the soluble form of the low density lipoprotein receptor-related protein (LRP). Exp. Cell Res. 251, 433-441. doi: 10.1006/excr. 1999.4590

Ramachandran, P. V., Mutlu, A. S., and Wang, M. C. (2015). Label-free biomedical imaging of lipids by stimulated Raman scattering microscopy. Curr. Protoc. Mol. Biol. 109, 30.3.1-30.3.17. doi: 10.1002/0471142727.mb3003s109

Sanchez, S. A., Gunther, G., Tricerri, M. A., and Gratton, E. (2011). Methyl$\beta$-cyclodextrins preferentially remove cholesterol from the liquid disordered phase in giant unilamellar vesicles. J. Membr. Biol. 241, 1-10. doi: 10.1007/s00232-011-9348-8

Selvais, C., D’Auria, L., Tyteca, D., Perrot, G., Lemoine, P., Troeberg, L., et al. (2011). Cell cholesterol modulates metalloproteinase-dependent shedding of LRP-1 (low-density lipoprotein receptor-related protein-1) and clearance function. FASEB J. 25, 2770-2781. doi: 10.1096/fj.10169508

Selvais, C., Gaide Chevronnay, H. P., Lemoine, P., Dedieu, S., Henriet, P., Courtoy, P. J., et al. (2009). Metalloproteinase-dependent shedding of lowdensity lipoprotein receptor-related protein-1 ectodomain decreases endocytic clearance of endometrial matrix metalloproteinase-2 and -9 at menstruation. Endocrinology 150, 3792-3799. doi: 10.1210/en.2009-0015

Simons, K., and Ehehalt, R. (2002). Cholesterol, lipid rafts, and disease. J. Clin. Invest. 110, 597-603. doi: 10.1172/JCI0216390

Swaroop, M., Thorne, N., Rao, M. S., Austin, C. P., McKew, J. C., and Zheng, W. (2012). Evaluation of cholesterol reduction activity of methyl- $\beta$-cyclodextrin using differentiated human neurons and astrocytes. J. Biomol. Screen. 17, 1243-1251. doi: 10.1177/1087057112456877

Takahashi, M., Murate, M., Fukuda, M., Sato, S. B., Ohta, A., and Kobayashi, T. (2007). Cholesterol controls lipid endocytosis through Rab11. Mol. Biol. Cell 18, 2667-2677.

Van Gool, B., Dedieu, S., Emonard, H., and Roebroek, A. J. M. (2015). The matricellular receptor LRP1 forms an interface for signaling and endocytosis in modulation of the extracellular tumor environment. Front. Pharmacol. 6:271. doi: 10.3389/fphar.2015-00271

von Tresckow, B., Kallen, K. J., von Strandmann, E. P., Borchmann, P. Lange, H., Engert, A., et al. (2004). Depletion of cellular cholesterol and lipid rafts increases shedding of CD30. J. Immunol. 172, 4324-4331. doi: 10.4049/jimmunol.172.7.4324

Zimina, E. P., Bruckner-Tuderman, L., and Franzke, C. W. (2005). Shedding of collagen XVII ectodomain depends on plasma membrane microenvironment. J. Biol. Chem. 280, 34019-34024. doi: 10.1074/jbc.M503751200

Conflict of Interest Statement: The authors declare that the research was conducted in the absence of any commercial or financial relationships that could be construed as a potential conflict of interest.

Copyright (c) 2016 Dekky, Wahart, Sartelet, Féré, Angiboust, Dedieu, Piot, Devy and Emonard. This is an open-access article distributed under the terms of the Creative Commons Attribution License (CC BY). The use, distribution or reproduction in other forums is permitted, provided the original author(s) or licensor are credited and that the original publication in this journal is cited, in accordance with accepted academic practice. No use, distribution or reproduction is permitted which does not comply with these terms. 